\title{
Vincent Kokich
}

O número de adultos que procuram tratamento ortodôntico é cada vez maior, na tentativa de melhorar a saúde periodontal, a capacidade mastigatória e obter uma estética agradável. Nestes últimos anos, os avanços na Ortodontia, Periodontia, Dentística Restauradora, Implantodontia e Odontologia Estética criaram novas perspectivas para estes pacientes. Invariavelmente, no planejamento do tratamento do paciente adulto, um trabalho interdisciplinar é necessário devido à sua complexidade. Com o intuito de aprofundar este tema, é com grande honra que apresentamos o Prof. Vincent Kokich, membro do Board Americano de Ortodontia e um dos maiores expoentes do tratamento interdisciplinar em adultos. Sua vasta experiência nesta área o tornou um dos conferencistas mais requisitados em todo o mundo, não só em congressos de Ortodontia, mas em áreas afins. Estabeleceu critérios clínicos que hoje servem de parâmetros no atendimento de pacientes adultos. Após anos de contato na tentativa de trazê-lo ao Brasil, fomos privilegiados com a sua participação recentemente no IV Encontro Internacional de Ortodontia promovido pela Coordenadoria de Pós-Graduação em Ortodontia da Faculdade de Odontologia da Universidade Federal de Goiás, ocasião em que concedeu esta entrevista.

Marcos Augusto Lenza

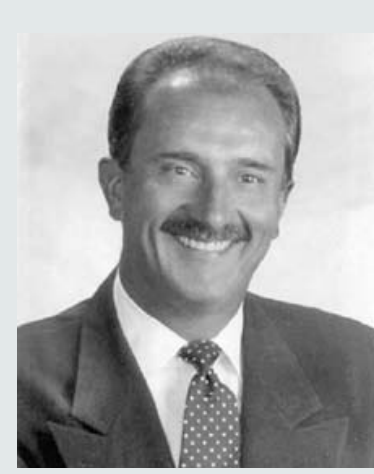

- Professor de Ortodontia da Faculdade de Odontologia da Universidade de Washington - EUA;

- Clínica particular em Tacoma, Washington - EUA;

- Ex-Presidente do American Board of Orthodontics;

- Ex-Presidente da American Academy of Esthetic Dentistry;

- Publicou 15 capítulos de livros e mais de 100 artigos científicos:

- Ministrou mais de 500 cursos em encontros e congressos de Ortodontia em vários países do mundo;

- Por sua excelência em Ortodontia, recebeu as seguintes premiações: Strang Award (1994), Salzmann Award (1996), Schluger Award (2000), Mershon Award (2001) e Dewel Award (2002);

- Pertence ao corpo editorial das seguintes revistas: American Journal of Orthodontics and Dentofacial Orthopedics, The Angle Orthodontist, Practical Reviews of Orthodontics, Journal of Esthetic Dentistry, Seminars in Orthodontics, Clinical Orthodontics and Research, Dental Traumatology, The Australian Dental Journal e The British Journal of Orthodontics.
1) Que critérios deve-se levar em consideração na fase de finalização do tratamento ortodôntico para se avaliar a forma e o contorno gengival na região anterior da maxila de tal forma a produzir o melhor resultado estético para o paciente? Marcos Augusto Lenza

Durante a fase de finalização ortodôntica, observo três fatores relacionados com o contorno gengival. Primeiramente, avalio os níveis relativos das margens gengivais dos dentes anteriores superiores. Em condições normais, as margens gengivais dos incisivos centrais e caninos superiores deveriam estar no mesmo nível e as margens gengivais dos incisivos laterais superiores deveriam estar posicionadas ligeiramente mais para incisal. Caso as margens gengivais não estejam relacionadas desta forma, pode ser devido a desgaste incisal ou extrusão, ou devido a um processo de irrupção ativo ou passivo alterado. Estes problemas podem ser diagnosticados avaliando-se a borda incisal em relação a desgastes ou à profundidade do sulco gengival para se determinar a posição da junção amelo-cementária, e a posição do osso alveolar relativa à junção amelo-cementária. Em segundo lugar, o contorno gengival dos dentes anteriores deveria ser suavemente arredondado semelhante à junção amelo-cementária destes dentes. 
Caso o contorno gengival seja achatado, é sugestivo de um problema de irrupção passiva ou ativa alterada. Em terceiro lugar, eu avalio a presença e posição da papila gengival entre os dentes anteriores. $\mathrm{O}$ nível da papila deveria estar a meia distância entre as bordas incisais e as margens gengivais. Se as papilas estiverem na posição correta, mas existir uma ameia aumentada ou um pequeno espaço negro entre os dentes anteriores, então é um problema de ponto de contato. Estas situações são geralmente tratadas alterando-se a angulação radicular, modificando o formato dos dentes ou restaurando-se os mesmos. Se a ameia aumentada for devido à perda da crista alveolar e perda da papila, pode-se alterar a anatomia dos dentes para comprimir o tecido interproximal ou promover a extrusão dos dentes adjacentes com desgaste seletivo das bordas incisais contribuindo assim para a solução deste difícil problema estético.

2) Quais os principais benefícios em se tratar ortodonticamente pacientes com problemas periodontais? Marcos Augusto Lenza

A terapia ortodôntica pode oferecer vários benefícios ao paciente adulto com problema periodontal. Primeiramente, pelo simples fato de se alinhar dentes anteriores superiores e/ou inferiores apinhados ou mal posicionados permitirá ao paciente adulto um melhor acesso para higienizar todas as superfícies dos seus dentes adequadamente. Isto poderia ser uma enorme vantagem para o paciente que é suscetível à perda óssea periodontal ou que não possui a destreza para manter sua higiene bucal de forma adequada. Em segundo lugar, o reposicionamento ortodôntico vertical de alguns dentes pode melhorar certos tipos de defeitos ósseos em pacientes com envolvimento periodontal. Nestes casos, geralmente o movimento dentário elimina a necessidade de uma cirurgia periodontal com remoção de tecido ósseo. Um terceiro benefício do tratamento ortodôntico é melhorar a relação estética dos níveis da gengiva marginal antes da Odontologia restauradora. $\mathrm{O}$ alinhamento das margens gen- givais ortodonticamente evita um procedimento periodontal cirúrgico, que em sua grande maioria poderia necessitar de remoção óssea e exposição das raízes dos dentes. Uma quarta vantagem da Ortodontia em alguns pacientes com problemas periodontais é devido à habilidade de se corrigir ameias gengivais abertas ou "espaços negros". Localizando-se na região anterior superior, eles são bastante comprometedores esteticamente. $\mathrm{Na}$ maioria dos pacientes, estas áreas podem ser corrigidas com a combinação do movimento ortodôntico radicular, alteração da forma do dente e/ou restauração estética, como mencionado anteriormente.

3) Um dos maiores desafios na clínica é tratar pacientes com envolvimento periodontal generalizado. Qual seria a sua abordagem de tratamento em pacientes que apresentam perdas ósseas horizontais significativas? Marcos Janson

O tratamento destes tipos de pacientes dependeria da localização da perda óssea, da quantidade de osso remanescente para suportar a raiz e coroa do dente, da habilidade do paciente em manter os dentes e em última análise, se o paciente poderia arcar com este tipo de tratamento. $\mathrm{Na}$ região do molar, uma perda óssea horizontal severa poderia expor a região de furca dos dentes, e a decisão de manter os molares ou substituí-los por implantes deveria ser determinada através de uma avaliação interdisciplinar entre o reabilitador, o periodontista e o ortodontista. Caso a perda óssea horizontal esteja localizada na região anterior superior, a estética do paciente estará afetada. No passado, uma cirurgia ressectiva agressiva era sempre realizada para se remover as bolsas periodontais profundas. Entretanto, este procedimento invariavelmente resultava em dentes anteriores longos e raízes expostas. Nos dias atuais, os periodontistas estão mais cautelosos para se evitar este tipo de cirurgia, preferem manter os dentes com o auxílio de uma manutenção periódica de rotina. Se a perda óssea ocorrer na região anterior inferior, desgastes seletivos das bordas inci- 
sais dos dentes auxiliarão na melhoria da proporção raiz/coroa sem afetar adversamente a estética. Os incisivos inferiores poderão ser mantidos indefinidamente caso o paciente e periodontista possam manter a higiene da área adequada e os dentes possam ser esplintados se necessário. Considero importante a minha interação com o periodontista e o reabilitador oral para tomar as decisões corretas em relação ao tratamento ortodôntico de pacientes com perdas ósseas horizontais.

4) Quais são os efeitos colaterais indesejáveis com os quais o ortodontista poderá se defrontar quando do tratamento de pacientes com perda óssea periodontal? Marcos Janson

Primeiramente, o paciente ortodôntico com problema periodontal deveria estar sob supervisão de um clínico geral ou preferencialmente de um periodontista se os problemas forem significantes. Os maiores desastres no tratamento ortodôntico de adulto acontecem naquele paciente com problema periodontal na fase ativa da doença, com aparelho ortodôntico em seus dentes e que não esteja sendo mantido ou supervisionado pelo periodontista ou clínico geral. Após o paciente ter se submetido a uma terapia inicial com o periodontista, tornará claro como o ortodontista poderá auxiliar na correção dos problemas periodontais existentes. Defeitos ósseos de uma ou duas paredes são passíveis de melhora com a extrusão ortodôntica. Entretanto, grandes perdas interproximais ou defeitos em três paredes não são melhorados com a extrusão ortodôntica. Comprometimentos de furca Classe II e III também não são passíveis de melhora com a movimentação ortodôntica. Perda óssea horizontal pode ser melhorada com Ortodontia se os dentes forem equilibrados durante o processo de alinhamento. Entretanto, o ortodontista deve planejar os objetivos do tratamento cuidadosamente para o paciente com perda óssea periodontal em conjunto com as opiniões do periodontista em relação ao nível de suscetibilidade da doença.
5) No preparo prévio do rebordo para colocação de implantes, a movimentação ortodôntica é realizada sobre rebordos atrofiados para a neoformação óssea na área oposta à movimentação do dente. Se neste rebordo atrofiado houver também um desnível vertical, é possível haver risco de perda óssea para o dente que está sendo movimentado nesta direção? Marcos Janson

Estudos em animais que testaram esta possibilidade já foram realizados. Se a movimentação dentária ocorrer de forma lenta o suficiente e se o paciente não tiver doença periodontal ativa na área, eu acredito que o osso sobre a raiz do dente próximo à área do defeito vertical não será comprometido pelo movimento na direção da área do defeito ósseo.

6) Em seus trabalhos foi relatado a necessidade de se obter pelo menos $1,5 \mathrm{~mm}$ de distância entre a plataforma do implante e os dentes adjacentes, na altura da crista óssea, para que a papila na interface dente-implante fosse preservada. Este protocolo permanece atual ou já surgiram implantes diferentes onde a perda óssea horizontal ao redor da plataforma não ocorre? Marcos Janson

A razão para se ter mais que um milímetro de osso entre o implante e o alvéolo do dente adjacente não está realmente relacionada com a perda óssea após o local do implante ter se remodelado. Antigamente acreditava-se que a perda óssea ao redor dos implantes continuava após a sua colocação e a espessura do osso sobre o implante reduziria a possibilidade de perda óssea. Entretanto, estudos longitudinais demonstram que os níveis ósseos são relativamente estáveis ao redor dos implantes com o passar do tempo. Entretanto, quanto maior for a distância entre o implante e o osso, será mais fácil criar uma papila entre os dentes naturais adjacentes. Isto é particularmente importante na região anterior da maxila. Portanto, é por este motivo que eu recomendo que pelo menos $1 \mathrm{~mm}$ seja mantido entre o implante e o dente adjacente, de tal forma a melhorar a estética da coroa definitiva quando comparados aos dentes naturais. 
7) Invariavelmente durante o exame clínico e radiográfico de pacientes adolescentes, o ortodontista se depara com agenesias de prémolares inferiores. Que critérios deveriam ser observados para se decidir pelo tratamento ortodôntico com conseqüente fechamento de espaço ou futura substituição por implantes? Marcos Augusto Lenza

A primeira questão a ser considerada é se o paciente necessita de tratamento ortodôntico. Se o paciente tiver ausência dos pré-molares inferiores mas tiver arcos dentários alinhados, em oclusão funcional e não necessitar de tratamento ortodôntico, eu manteria os molares decíduos desde que eles não estivessem anquilosados. Caso o paciente possuísse uma má oclusão com indicação de tratamento ortodôntico, então o perfil do paciente, a quantidade de apinhamento, o grau de protrusão dentária e outros fatores esqueléticos ou dentários auxiliariam na decisão de prosseguir com o fechamento de espaço ou substituir os dentes ausentes por implante. Entretanto, hoje temos outra possibilidade, ou seja, o uso de implantes temporários que servem de ancoragem ortodôntica para o fechamento de espaço edêntulo resultante da ausência congênita dos segundos pré-molares inferiores mesmo se o paciente não possuir uma má oclusão. É claro que, com esta decisão, poderemos ter que alterar o padrão oclusal, mas devemos considerar esta possibilidade em alguns pacientes. O fechamento de espaço de um segundo pré-molar ausente com implante servindo de ancoragem pode levar um tempo considerável. Por outro lado, os implantes no arco inferior são previsíveis e não podem ser considerados como tratamentos radicais para a substituição de segundos pré-molares ausentes quando adequadamente indicados. Nestas situações, é geralmente útil para o ortodontista, reabilitador oral e paciente ou pais discutir todas as opções e optar por uma solução que seja a mais adequada para cada paciente. Em outras palavras, o ortodontista não deveria tomar uma decisão final independentemente.
8) Da mesma forma, em pacientes com agenesia de incisivos laterais superiores, duas opções de tratamento estão disponíveis: abertura de espaços e implantes na região das agenesias ou fechamento de espaços e substituição dos laterais ausentes pelos caninos permanentes. Qual a sua preferência e em que condições estas alternativas poderiam ser indicadas? Ademir Roberto Brunetto

Muitos pacientes possuem agenesias dos incisivos laterais superiores. Caso este problema venha a ocorrer, existem duas opções gerais de tratamento. A primeira opção constitui na abertura de espaço para um pôntico ou implante e a outra opção envolve a substituição dos laterais superiores pelos caninos permanentes e fechamento de todo espaço superior edêntulo. Três critérios deveriam ser avaliados antes de se escolher esta opção de tratamento. Primeiramente, a oclusão ou má oclusão do paciente deve ser considerada. A situação ideal para substituição do canino é o paciente com uma relação molar de Classe II, apinhamento mínimo dos dentes inferiores e um aceitável perfil facial. A substituição dos incisivos laterais ausentes pelos caninos eliminará a necessidade de qualquer reabilitação maior. $\mathrm{O}$ segundo critério para selecionar a substituição pelo canino é a discrepância do canino em relação aos dentes anteriores. Quando os incisivos laterais são substituídos pelos caninos, um excesso na região superior é criado. A largura dos seis dentes anteriores superiores geralmente tem que ser reduzida em tamanho para se criar uma relação de overbite e overjet correta. Um set-up de diagnóstico é necessário para se determinar se a substituição pelo canino é um plano de tratamento razoável para a ausência congênita dos laterais. O terceiro critério é o comprimento, formato e cor das coroas dos caninos superiores. Casos os caninos sejam os substitutos dos incisivos laterais, as suas margens gengivais devem estar posicionadas mais para incisal em relação aos incisivos centrais, porque os comprimentos das coroas dos incisivos laterais são tipicamente menores que os incisivos centrais. Portanto, os caninos devem ser extruídos e 
suas cúspides desgastadas para se criar a ilusão que eles são os incisivos laterais. Se a forma da cúspide do canino for muito longa e pontiaguda, pode ser impossivel reduzir a cúspide o suficiente para simular a borda incisal do incisivo lateral. Um dos aspectos mais difíceis que se depara em relação à forma do canino é solucionar o contorno vestibular. Alguns caninos superiores têm as superfícies vestibulares relativamente achatadas. Estes se assemelham mais ao contorno vestibular dos incisivos laterais. Entretanto, outros caninos superiores possuem superfícies vestibulares convexas ou arredondadas. É um desafio fazer com que estes dentes se pareçam como laterais devido ao contorno vestibular arredondado. Uma reanatomização da superfície vestibular com porcelana ou com coroa veneer de resina composta criará um resultado estético muito mais aceitável.

9) Após o surgimento dos implantes ósseointegrados, a porcentagem de casos de agenesias de laterais tratados com substituição por implantes aumentou ou permaneceu a mesma? Marco Antônio Almeida

Em termos gerais não tenho condições de responder esta questão em relação aos outros ortodontistas em suas clínicas particulares, mas com toda a certeza este fato afetou a porcentagem de pacientes que eu trato criando espaço ao invés de fechar o espaço com a substituição pelo canino. Atualmente, este procedimento de abrir espaço para mim é mais comum do que fechar espaço. Entretanto, minhas decisões ainda são baseadas em fatores que foram mencionados anteriormente. Na situação correta, uma coroa de veneer em porcelana na superfície vestibular de um canino superior pode ser mais estética que um implante na região do incisivo lateral.

10) Como o senhor classificaria o resultado final estético da substituição de um lateral congenitamente ausente por um implante - excelente, bom, satisfatório ou não satisfatório? Marco Antônio Almeida
Novamente, não tenho condições de responder esta pergunta em relação aos outros ortodontistas em suas clínicas particulares, mas posso responder a esta pergunta do ponto de vista pessoal. Eu e meus colegas, periodontista e o reabilitador oral, temos colocado implantes na região dos incisivos laterais superiores por quase 15 anos. Neste período, pudemos presenciar melhorias nos materiais, técnicas cirúrgicas, na nossa compreensão sobre biologia e métodos restauradores. Como conseqüência, temos visualizado uma grande melhoria em nossos resultados. Em recentes congressos, quando tive a oportunidade de abordar este tema em relação a implantes de incisivos laterais superiores, eu regularmente mostro uma série de 10 a 15 casos de implantes de incisivos laterais superiores para uma platéia de cirurgiões-dentistas e ortodontistas e pergunto a eles se podem me apontar qual dente é o implante e qual é o dente natural. É completamente impossivel fazer esta distinção. Entretanto, meus colegas e eu aprendemos muito nestes últimos 15 anos e sabemos o que é necessário para produzir um implante com este grau de perfeição. $O$ ponto que quero enfatizar, é que existe um grande processo de aprendizado em se restaurar um dente ausente por um implante. Ortodontistas e reabilitadores podem melhorar as suas habilidades técnicas unindo-se a grupos de estudo sobre implantes, o que os ajudará a aprender as qualificações necessárias para produzir um excelente resultado.

11) Nas décadas de 1960 e 1970, a Ortodontia se aproximou da Cirurgia Oral, principalmente devido à Cirurgia Ortognática. $\mathrm{Na}$ década de 1980, os elos com a Periodontia e Prótese foram fortalecidos. Nos anos 90 , integramos os implantes em nossos tratamentos. Quais as diretrizes que o tratamento interdisciplinar provavelmente seguirá nos próximos anos? Jorge Faber do Nascimento

Acredito que a resposta para esta questão dependerá parcialmente dos avanços no campo da Periodontia, Dentística Restauradora, Implantodon- 
tia, Odontologia Estética, e também em relação aos tipos de pacientes que procurarão pela Ortodontia no futuro. $\mathrm{O}$ estímulo para a era odontológica interdisciplinar nos últimos 10 anos foi a procura de tratamento ortodôntico por pacientes adultos em todo o mundo. Nos Estados Unidos, não é pouco comum que as clínicas ortodônticas possuam de 40 a 50\% de pacientes adultos. Pacientes nesta faixa etária trouxeram um conjunto de problemas totalmente diferente para o ortodontista e fizeram com que o ortodontista trabalhasse mais próximo de seus colegas periodontistas e reabilitadores orais. Ao mesmo tempo, estética e implantes tiveram um surto de desenvolvimento em Odontologia e, agora, pacientes adultos em todo o mundo desejam dentes alinhados e mais brancos. Como resultado, o ortodontista foi incorporado nesta crescente parcela da Odontologia. Acredito que esta tendência irá crescer mais ainda no futuro e exigirá que os ortodontistas compreendam como lidar com estes tipos de pacientes.

12) Suas pesquisas trouxeram novos conceitos de integração entre a Ortodontia e as outras especialidades. Quais são os tópicos que o senhor tem trabalhado no momento? Jorge Faber do Nascimento

Um projeto de pesquisa que estamos trabalhando na universidade é avaliar um grupo de pacientes com caninos impactados por palatino que foram expostos precocemente e permitido que irrompessem no palato antes de movimentá-los para a arcada dentária. Esta é a técnica que eu e meu colega David Mathews temos usado nos últimos 15 anos. Agora nós já temos uma amostra de pacientes que já chamamos para uma reavaliação sobre os aspectos periodontais e estéticos desta técnica. Nós deveremos terminar este projeto e submetê-lo para publicação em 2005.

13) Em sua clínica particular, que porcentagem de pacientes necessitam de tratamento interdisciplinar? Jorge Faber do Nascimento

Primeiramente, a minha clínica é limitada a pacientes adultos ou adolescentes com problemas restauradores ou periodontais. Portanto, a maioria dos pacientes que eu trato necessitam de minha interação com o reabilitador oral, periodontista, cirurgião oral ou endodontista. Por esta razão, eu tenho uma clínica pequena com apenas três cadeiras odontológicas. É muito pequena em relação à maioria das clínicas de Ortodontia dos Estados Unidos. Entretanto, com mais casos que configuram um verdadeiro desafio à prática diária e a necessidade de se tomar decisões mais difíceis com o paciente que está na cadeira, eu acho que é verdadeiramente impossível tratar de um grande número de pacientes adultos com necessidades interdisciplinares e esperar obter resultados excelentes.

14) O planejamento de muitos tratamentos interdisciplinares inclui a confecção de uma simulação de tratamento em set up. É um procedimento trabalhoso, mas fundamental. Quantas simulações de tratamento são feitas em média em sua clínica particular? Jorge Faber do Nascimento

Uma simulação de tratamento em set up é necessária quando o paciente tiver ausência de múltiplos dentes ou quando a extração de dentes puder provocar alguma desarmonia oclusal. Caso o paciente adulto tenha todos os dentes e não haja previsão de extração de dentes, um set up é raramente necessário. Entretanto, no paciente adulto ou adolescente quando vários dentes permanentes estão ausentes e serão substituídos por implantes, próteses ou através do fechamento ortodôntico do espaço, os membros da equipe interdisciplinar devem ter a mesma visão do final do tratamento antes mesmo que ele se inicie. $\mathrm{O}$ único modo possível é através da construção de um set up de diagnóstico. $\mathrm{O}$ ortodontista deve compartilhar sua opinião com o reabilitador e algumas vezes com o periodontista antes que sejam tomadas as decisões apropriadas sobre a posição final do dentes. Deste modo, é definitivamente um trabalho de equipe, mas a responsabilidade de se construir o set up é do ortodontista. 
15) O senhor foi um dos precursores do uso da ancoragem ortodôntica esquelética. Qual o papel dos mini-implantes e mini-placas como ancoragem ortodôntica no futuro da Ortodontia? Jorge Faber do Nascimento

Ancoragem esquelética está revolucionando o modo como os ortodontistas planejam o tratamento de más oclusões difíceis. Isto é bom e ruim. A ancoragem esquelética pode permitir ao ortodontista realizar muitos tipos de movimento dentário que não são possíveis com ancoragem dentária ou extrabucal convencional. Isto é bom. Entretanto, só porque é possível alcançar um certo tipo de movimento dentário, pode não significar que é melhor para o paciente. Isto é especialmente verdade se o paciente necessitar de futuro tratamento restaurador ou periodontal. Nestas situações, o ortodontista deve mesmo assim, discutir as várias possibilidades ortodônticas de tratamento com o reabilitador oral e periodontista e sugerir o uso da ancoragem esquelética e o que pode ser realizado. A equipe deveria decidir se o efeito do tratamento gerado pela ancoragem esquelética é melhor para o paciente em relação à futura saúde oclusal, reabilitadora e periodontal.

16) Recentemente, foi criado o Board Brasileiro de Ortodontia. Por ter sido presidente e membro do Board Americano de Ortodontia por muitos anos, que motivos levariam um ortodontista a procurar sua certificação pelo Board? Marcos Augusto Lenza

Numa definição clássica da certificação pelo Board, que existe nos Estados Unidos há 75 anos, este objetivo clínico da certificação constitui o nível mais alto que um ortodontista pode alcançar em sua carreira clínica. Obter a certificação pelo Board, dará ao ortodontista a oportunidade de sistematicamente rever seu trabalho, aprender através de seus erros e receber a honra por completar o processo. Entretanto, não é isto o que a certificação pelo Board significa hoje nos Estados Unidos nos campos da Medicina, Odontologia e
Ortodontia. Hoje, em todas as outras áreas das profissões de saúde, a certificação pelo Board é o estágio inicial de conquista que todos os alunos de pós-graduação alcançam pouco tempo depois do término do programa de pós-graduação odontológica ou médica. O termo re-certificação foi desenvolvido nos últimos 15 anos como um método de se avaliar a contínua competência do clínico em sua profissão. Este processo de re-certificação foi introduzido na Ortodontia em 1999. No futuro, os ortodontistas provavelmente obterão a sua certificação muito cedo em suas carreiras clínicas, mas serão requisitados a obter a sua re-certificação ocasionalmente em sua carreira. Certificação e re-certificação são basicamente o mesmo processo e ambos são essenciais para qualquer profissional clínico. É simplesmente um processo de auto-exame: o processo de olhar o trabalho clínico e aprender como se aperfeiçoar. Eu pessoalmente acredito que o novo sistema de re-certificação e revisão contínua do seu trabalho é um modo muito mais realista de melhoria das qualidades clínicas. Entretanto, a incorporação deste processo em Ortodontia levou anos nos Estados Unidos e continuará a ser refinado no futuro.

17) A busca da certificação pelo Board Americano de Ortodontia seguramente eleva a qualidade média de todos os tratamentos realizados pelo profissional. Todavia, nem todos os tratamentos são finalizados com a excelência necessária para obter aprovação. Baseado em sua experiência como examinador do Board e como clínico, qual a porcentagem aproximada de casos finalizados por um bom profissional que atenderia aos padrões de excelência exigidos? Jorge Faber do Nascimento

$\mathrm{Na}$ realidade, baseado no sistema de graduação do Board Americano de Ortodontia para modelos de gesso e radiografias panorâmicas, qualquer ortodontista pode medir o nível de qualidade que produz regularmente em sua clínica particular. Este é o modo como utilizo este sistema. A cada 6 meses, 
eu avalio 10 modelos ortodônticos de tratamentos consecutivos realizados. Eu conheço o número de pontos necessários para se obter o padrão de excelência no exame pelo Board. Eu acredito que deveria ser capaz de obter estes padrões em 8 ou 9 dos 10 casos a cada 6 meses. Eu venho realizando este tipo de auto-avaliação nos últimos 6 anos. Através deste sistema, eu sei exatamente da perfeição como trato os casos e isto também faz com que eu saiba onde eu preciso me aperfeiçoar, isto porque este

\footnotetext{
Ademir Roberto Brunetto

- Pós-graduado em Ortodontia pela Universidade da Califórnia - Los Angeles (UCLA).

- Ex-Professor da Disciplina de Oclusão da Universidade Federal do Paraná (UFPR).

- Professor de Graduação e Pós-graduação em Ortodontia da Universidade Federal do Paraná (UFPR).

- Professor convidado do Curso de Especialização em Periodontia da ABO - PR.
}

\section{Jorge Faber do Nascimento}

- Doutorado em Biologia Animal - Morfologia pela Universidade de Brasília, UNB.

- Mestrado em Odontologia (Ortodontia) pela Universidade Federal do Rio de Janeiro.

- Clínica privada voltada para o atendimento de pacientes adultos.

\section{Marco Antonio de Oliveira Almeida}

- Professor Titular de Ortodontia UERJ.

- Research Fellow Universidade da Carolina do Norte.

- Mestre em Ortodontia UFRJ.

- Livre Docente em Ortodontia UERJ.

- Coordenador do Curso de Mestrado em Ortodontia UERJ. sistema de avaliação demonstra onde os erros foram cometidos. O Board reconhece que é impossivel tratar qualquer caso perfeitamente. Mesmo assim, o Board tem estabelecido um certo grau de excelência. O Board também proporciona ao clínico, um sistema de pontuação para que ele mesmo possa medir, rotineiramente em suas clínicas particulares, o seu nível de qualidade. Para mim, este é o melhor método para se alcançar o mais alto nível de excelência clínica.

\section{Marcos Augusto Lenza}

- Mestre e Doutor em Ortodontia pela Universidade de Nebraska - Estados Unidos.

- Professor Titular de Ortodontia da Faculdade de Odontologia da Universidade Federal de Goiás.

- Coordenador do Programa de Mestrado em Odontologia da Faculdade de Odontologia da Universidade Federal de Goiás.

- Coordenador do Curso de Especialização em Ortodontia da Faculdade de Odontologia da Universidade Federal de Goiás.

\section{Marcos dos Reis Pereira Janson}

- Especialista em Ortodontia pela Faculdade de Odontologia de Bauru - USP.

- Professor dos cursos de Periodontia, Prótese e Ortodontia da Faculdade de Odontologia de Bauru - USP.

- Mestrando em Ortodontia pela Faculdade de Odontologia de Bauru - USP. 